\title{
Numerical Modeling of Sediment Transport Rate and Shoreline Changes of Jazireh-e Shomali-Jonoubi Port in the Persian Gulf
}

\author{
Milad Bamdadinejad ${ }^{\text {a }}$, Mohammad Javad Ketabdari ${ }^{\text {b,* }}$ and Farhad Shojaei ${ }^{\text {a }}$ \\ a) Coastal Engineering, Department of Maritime Engineering, Amirkabir University of Technology, Tehran, Iran \\ b) Assistant Professor, Department of Maritime Engineering, Amirkabir University of Technology, Tehran, Iran \\ *Corresponding author: Ketabdar@aut.ac.ir
}

\section{Paper History}

Received: 06-April-2020

Received in revised form: 18-June-2020

Accepted: 30-July-2020

\begin{abstract}
Studying the sediments and predicting the coastal morphological changes have wide applications in coastal engineering, including coastal management, operation, and design of the structures as well as their maintenance, development, and expansion of coasts and coastal structures, which are of paramount importance. The aims of this study are to model the shoreline changes around the Jazireh-e ShomaliJonoubi Port, calculate the amount of advancement and recession due to the construction of the breakwater, and to determine the areas exposed to erosion and sedimentation. To this end, a series of primary information, including aerial and satellite images, hydrographic and topographic maps, and the specifications and grading of the sediment of the considered coast, has been collected and the overall morphology of the area has been determined. The input data into the model include a 12-year time series of the wave (height, period, and direction of the wave) and the wave climate. The length of the shoreline is $4 \mathrm{~km}$ and a profile perpendicular to the coast with a length of $1500 \mathrm{~m}$ has been applied to the model. Finally, using numerical modeling, the net and gross potential rates of annual and cumulative sediment transport, as well as shoreline changes after 12 years, were simulated. The effect and length of sedimentation behind the port's breakwater after 1, 5, 10 and 12 years are 81, 190, 247 and 267 meters, respectively, which is in good agreement with the actual observations. Considering the fact that the length of the breakwaters is 300 meters, the sedimentation problem has not yet been established for the port after 12 years.
\end{abstract}

KEY WORDS: shoreline changes, numerical modeling, sediment transport rate, non-cohesive sediments.

\author{
NOMENCLATURE \\ $y_{c}(x) \quad$ Distance from the baseline to the shoreline \\ $t \quad$ Time \\ $h_{a c t}(x)$ The height of the active cross-shore profile \\ $Q(x) \quad$ Longshore sediment transport \\ $x \quad$ Longshore position \\ $\Delta x \quad$ Longshore discretization step \\ $Q_{\text {sou }}(x)$ Source or sink term per unit volume
}

\subsection{INTRODUCTION}

The term "morphology" means the study of shapes and forms and is not just limited to coasts and marine investigations. In the area of marine projects, morphology generally refers to the studies concerning the interaction between coastal bed changes and hydrodynamic conditions, including wave, flow, bed slope, and grading characteristics of the bed. Coastal environment is one of the most important environmental systems that rapidly changes under the influence of hydrodynamic processes and perhaps, is not comparable with other geomorphologic systems (Yamani and Nohegar, 2006). The shoreline is one of the most important features on the Earth's surface, which is dynamic in nature (Winareso and Budhiman, 2001). Therefore, the International Geographical Union treats coastal areas as a unique natural environment (Rasuly et al., 2010). Therefore, in the study of coastal geomorphology, we confront another form of dynamic events (Ahmadi, 2011). Coastal areas are also very important in terms of environmental issues, as they have sensitive and productive ecosystems (Kouroshinia, 2010). Monitoring coastal areas is an important parameter in sustainable development and environmental protection. In order to monitor coastal areas, it is necessary to extract the coast at different times. Different reactions occur in coastal areas because they are located in two different climates of land and water (Kaviani, 2001). 
Familiarity with coastal processes, prediction of sedimentation or erosion and assessment of shoreline changes are of importance in different aspects of management and engineering. This is because the operation and performance of coastal structures and facilities are strongly dominated by these processes. On the other hand, the above-mentioned information serves as an indicator for environmental and economic assessment of projects and permits a feasibility study on the sustainable development of the coasts through integrated coastal management (Barter et al. 2003). Coastal morphology is the result of complex dynamic processes at different scales, including waves, flows, and sediment transport against changes in the bed (Baquerizo and Losada, 2008). Studies are conducted on both regional and local scales for local coastal management and engineering applications, especially to assess the long-term performance of coastal facilities (Larson et al. 2002; Shanehsazzadeh et al. 2012; Sabatier et al. 2009).

Sediment studies are an essential part of coastal construction projects studies nowadays. In this regard, employing empirical models and specialized software are common approaches. However, disregarding the sedimentation capacities and the history of shoreline changes, have made the predictions based on raw results of these models unrealistic and unusable in many cases, and have ultimately made the longterm performance of the structures problematic. Nowadays, the prediction of shoreline changes based on conceptual models and the use of empirical and numerical models merely as a means to quantify them is a dominant approach (De Vriend, 1991).

Numerous studies have been conducted hitherto on numerical modeling of sediment transport rates and shoreline changes in different countries (Irtem et al. 2000; Boak and Turner, 2005; Ngoc Thach et al. 2007; Kulkarni, 2013; Townsend et al. 2014; Hendriyono et al. 2015; Rajasree et al. 2016; Hopkins et al. 2017; Ensign et al. 2017; Jackson et al. 2017; Gopikrishna et al. 2018). Ruggiero and McDougal (2001) presented an analytical model to predict longshore sediment transport rates in presence of a seawall. The authors used an energetic method to obtain the longshore sediment transport rate by applying the coefficient of the wall effect and calculated this rate under the influence of the seawall. Kumar et al. (2003) studied the equations of the longshore sediment transport rate, including the CERC equations Walton, (1984) and Chiu, (1979) and the Transport program (Van Ryne ,1989), on the west coast of India. The analysis of the measurement results showed that this method leads to the most accurate prediction. Bayram et al. (2007) introduced a new formula for the longshore sediment transport rate, which, unlike other existing formulas, does apply the effect of the wind-induced currents on the longshore transfer rate. These researchers described the work needed to suspend the grains as an integral of the product of sediment concentration and submerged weight and the fall speed of the particles. Using the definition of energy flux and by assuming an average speed in the breaking zone, they achieved a formula for the longshore sediment transport rate. Li et al. (2007) presented a quasi-threedimensional numerical model to predict the sediment transport rates. In this model, the wave characteristics are firstly determined by solving equations of continuity and momentum. Then, the wave-induced current is calculated by applying wave-induced stresses in the momentum and continuity equations. After that, using a one-dimensional vertical model, the sediment transport process is analyzed. Esteves et al. (2009) provided a semi-empirical model for predicting the longshore transfer rate. The authors used field measurements of sediment transport on the beaches of Brazil, Denmark, and Portugal. Some key environmental parameters were extracted from theoretical relations. Also, some simplifications were assumed in the wave's characteristics and cross-shore distribution of the sediment. By comparing the new model with Bayram et al. (2007) method, the researchers proved that this model is $30 \%$ more accurate than the previous one. Brown and Davies (2009) presented methods for estimating the medium-term sediment transport by the wave and current in complex coastal areas. They applied the Telemac modeling system to the Wales shores to reconstruct the wave and annual tidal conditions and the resulting sediment flux. This model consists of three parts of "Flow field estimation", "Wavefield estimation" and "Estimation of sediment transport and bed morphology", which are implemented as a repeated cycle.

\subsection{STUDY AREA}

Jazireh-e Shomali-Jonubi is a residential area of the city of Ganaveh. This area leads to the Dareh-Gachi River and city of Rig from the north and is located about $130 \mathrm{~km}$ of Bushehr. Jazireh-e Shomali-Jonubi Port lies between two coastal villages of Jazireh-e Shomali and Jazireh-e Jonubi. The mentioned villages are located on the mainland coast and are located $8 \mathrm{~km}$ south of Bandar Rig and on no account are conceived to be the island. The direction of the Persian Gulf coast in this region is "North-South" up to about $10 \mathrm{~km}$ south of the studied port and is "Northwest-Southeast" up to approximately 10 kilometers north of the studied port. The selected Jazireh-ye ShomaliJonubi location is placed in the geographical coordinates of $29^{\circ} 25^{\prime} 29^{\prime \prime}$ north and $50^{\circ} 39^{\prime} 24^{\prime \prime}$ east. Figure 1 shows the domain under study.

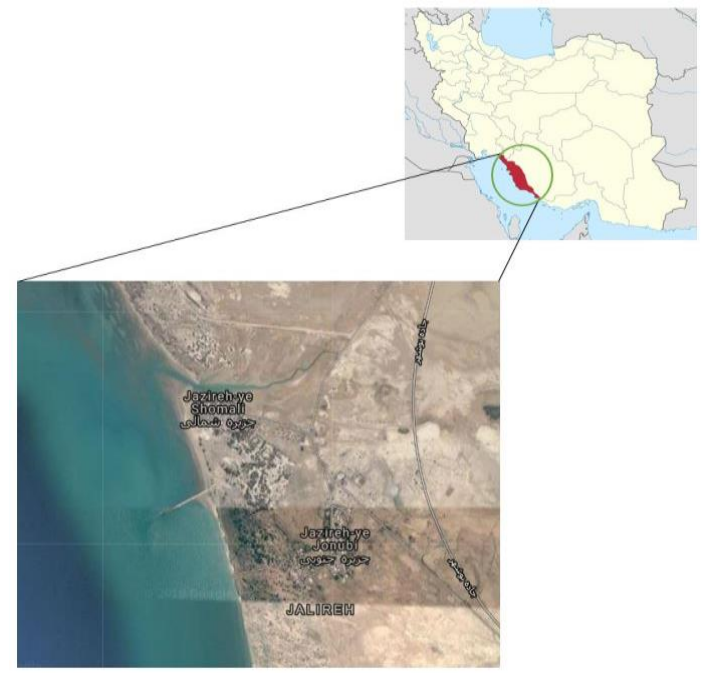

Figure 1: The study area

The coasts of Jazireh are of sandy landform type. By moving north and approaching the Jazireh-ye Shomali village, the amount of fine-grained sediment (silt) increases, which is due to the carryovers of the Shoor River in the past that used to run into the Koohak Estuary. The river has now diverted and flows into the Persian Gulf at a distance of 10 kilometers south of the studied port. By moving toward the Southern Jazireh-ye Jonubi village, the coasts gradually become rocky and then retake the shape of sandy beaches again. Also, small amounts 
of fine-grained sand sediments are displaced by wind in this region. However, this type of sediment transport is greatly reduced due to the vegetation of the hinterland and farming in the surrounding lands.
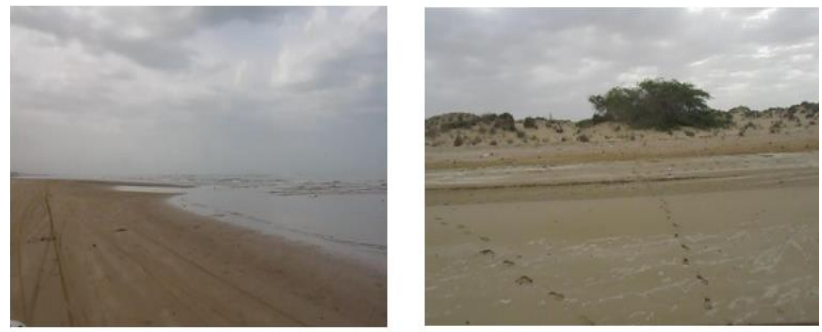

Figure 2: The status of the coast in the studied area

\subsection{MATERIALS and METHODS}

In order to carry out the wave-related calculations, the wind corresponding to the universal wind model has to be simulated firstly using the two-dimensional wave model and the information about the formation of the wind-induced wave must be extracted. However, since the wave information derived from modeling of the Iran sea waves is available, this step has been skipped.

The data on the region waves are the results of the Iran Sea Wave Modeling (ISWM) project. The time series data include information about altitude, period, and direction of the waves. The resulting wave rose diagram is drawn by $22.5^{\circ}$ circular sectors and organizing the wave heights into the 0.3 -meter span, as shown in Figure 2.

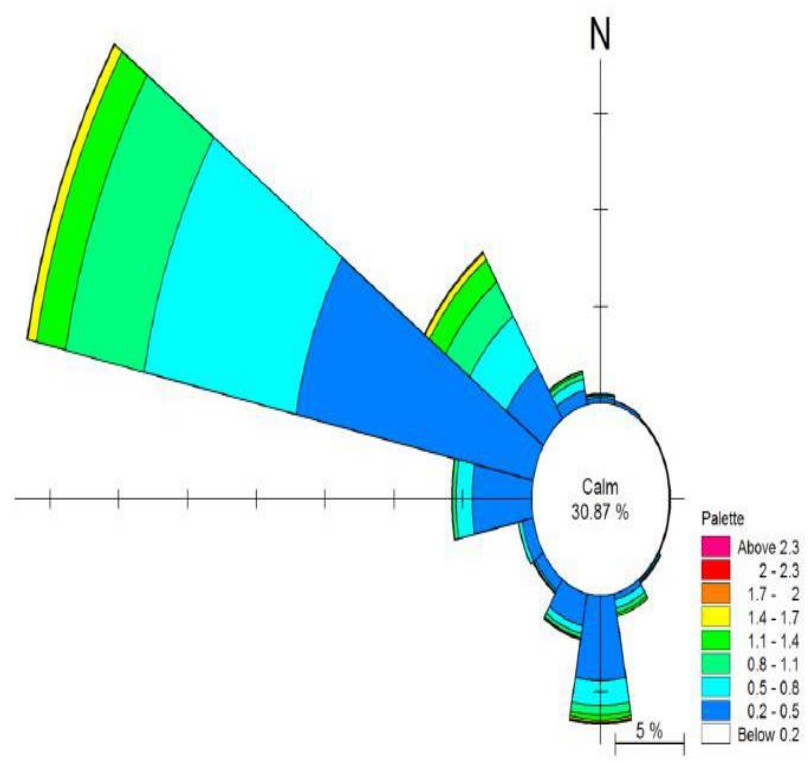

Figure 3: 12-year annual wave rose with $22.5^{\circ}$ circular sectors

Before simulating the studied area, it was decided to examine the satellite images of the area in order to obtain information such as the sedimentary resources of the port as well as the sediment transport pattern of the area. The satellite images depicted in Figure 4 are obtained from Google and display the studied area and sedimentary resources clearly.

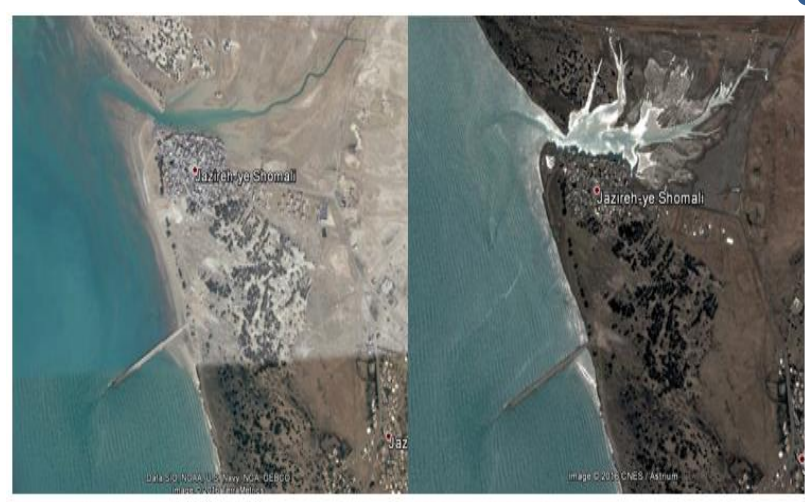

(a)

(b)

Figure 4: Satellite images of the studied area in the year: a) 2013; and b) 2016

In order to perform the simulations, the LITPACK module of the MIKE21 software has been used, which simulates the changes in a one-dimensional manner to increase the computational speed. However, due to the simplifications made in these models, the accuracy of the two-dimensional methods is not achievable. In this paper, modeling of the sediment transport and shoreline changes in the Jazireh-e ShomaliJonoubi port are carried out and then, the sedimentation and erosion conditions are investigated within the domain of the considered project. To this end, the information and the relevant studies about this field, including aerial and satellite images of the region, hydrographic and topographic maps, and the characteristics and grading of the sediment in the considered coast have been collected and the overall morphology of the region is determined. Afterward, based on the available evidence and information, the sedimentation and erosion patterns around the port are estimated and the useful life of the port and its maintenance conditions are discussed.

As mentioned previously, the LITPACK model was used for the simulation. This software performs the simulations on normal lines to the coast that contain points with short spacing and then calculates the values of the shoreline advancement or recession by interpolation of the results between these lines. This model is categorized as a one-line model that uses the following general formula:

$$
\frac{\partial y_{c}(x)}{\partial t}=-\frac{1}{h_{a c t}(x)} * \frac{\partial Q(x)}{\partial x}+\frac{Q_{s o u}(x)}{h_{a c t}(x) \cdot \Delta x}
$$

In Equation (1), $y_{c}(x)$ is the distance from the baseline to the shoreline, $t$ is the time, $h_{a c t}(x)$ is the height of the active cross-shore profile, $Q(x)$ is the longshore sediment transport, $x$ is the longshore position, $\Delta x$ is the longshore discretization step and $Q_{\text {sou }}(x)$ is the source or sink term per unit volume.

The input data into the model include a 12-year time series of the wave, whose wave rose is shown in the previous section. The coastline is $4 \mathrm{~km}$ long and a cross-shore profile with a length of 1500 meters has been applied to the model. The information about the coastal profile is extracted from the formula in Coastal book in the form $y=A x^{2} / 3$. The values of A can also be measured according to the grading and pattern of the coast. The distance between every two points along the coast and the coastal profile is considered to be is 10 meters and 5 meters, respectively. As a result, the coastal profile is obtained as Figure 5. 


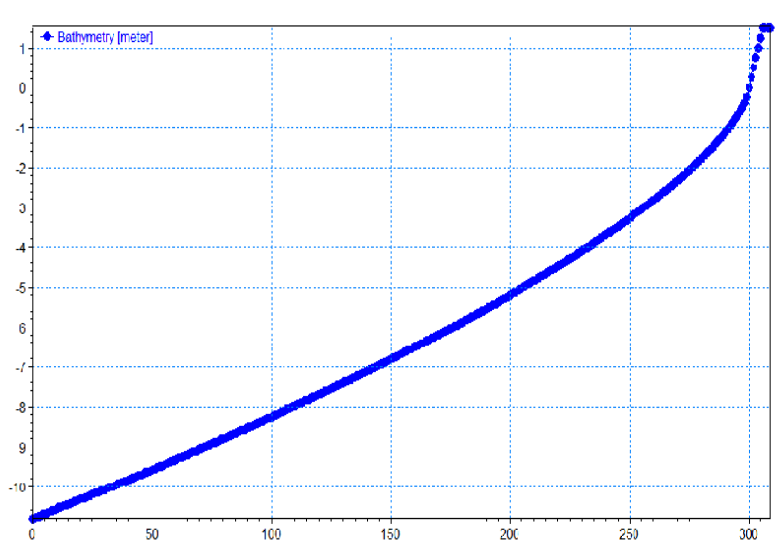

Figure 5: Cross-shore profile of the studied area

Since the size of the sediment particles is $0.11 \mathrm{~mm}$, and according to the suggestion of the MIKE software that the considered roughness should be 50 times the diameter of the particles, the roughness value is considered to be 0.0055 . Given the particle size and the $22^{\circ} \mathrm{C}$ temperature for seawater and according to the Coastal Engineering Manual (CEM), the particle fall speed is considered to be $0.01 \mathrm{~m} / \mathrm{s}$. The density of seawater and sediments are assumed 1020 and $2650 \mathrm{~kg} / \mathrm{m}^{3}$, respectively. The shoreline information is also applied to the model as follows:

The coast is introduced to the model as a straight line that is 100 meters ahead of the baseline. As can be observed in Figure 4 , the assumption of a straight coastline in the Jazireh-e Shomali region can be reasonable. Since no information is available about the coastal dunes, their value is not included in the model. It is also assumed that at the beginning of the simulation, the depth contours in the deep water are parallel to the coastline. The Active Depth parameter is set to 4.5 meters (this parameter specifies how much of the coastal profile can experience erosion or sedimentation below the mean water level). This parameter is also not precisely known and could be accurately identified and introduced to the model by calibrating the model.

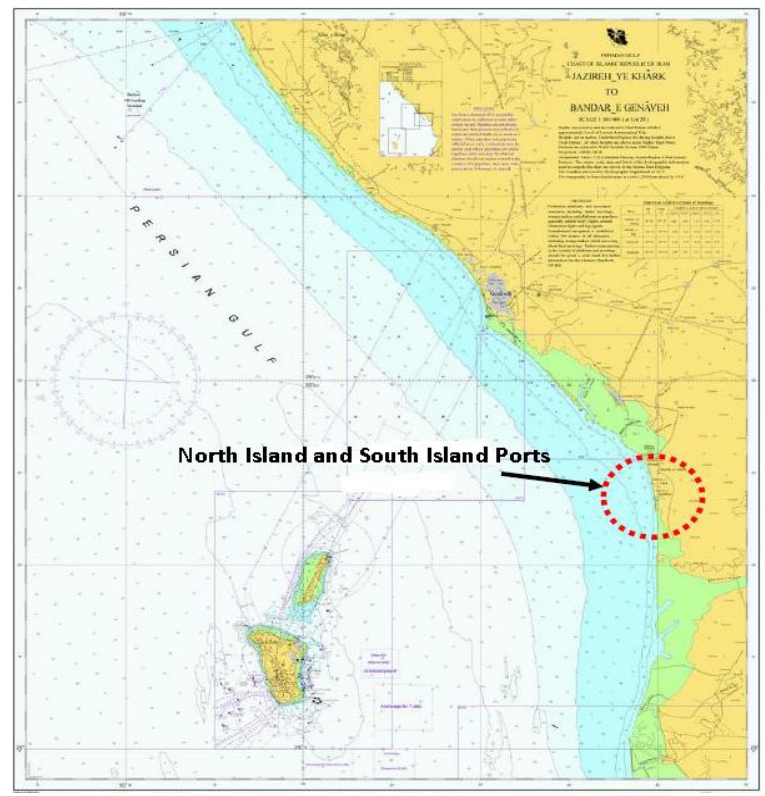

Figure 6: Hydrographic map of Jazireh-e Shomali-Jonoubi Port with a scale of 1:100000
Hydrographic maps have been prepared with different scales from the considered area. The only map from the Cartographic Organization that covers the hydrography of Jazireh-e Shomali-Jonoubi with a precision of 1:100,000 is shown in Figure 5. Also, a hydrographic map with a precision of 1:1000 was prepared earlier in the coastal area of Jazireh Port. The final hydrograph map obtained from depth measurement data with scales of 1:1000 and 1:100000, which also includes the Bandar Rig breakwater, is shown in Figure 6.

\subsection{RESULTS and DISCUSSION}

In this section, it has been attempted to calculate the potential of sediment transfer rate in the Jazireh-ye Shomali-Jonubi region. Sediment transport occurs in a coastal area, however, sediment transport in the longshore direction is the main cause of the problems for ports and sometimes the estuary. Of course, the sediment transport also occurs in the cross-shore direction, and this occurs when the approaching wave is perpendicular to the coast. In this case, the sediments are transported to the sea in the cross-shore direction only by hurricanes, and when the calm waves dominate the sea, the sediments are again transferred to the coast. Nevertheless, when the approaching wave is oblique to the coast, longshore transfer takes place. The most important factor contributing to the longshore sediment transport is the existence of the flows parallel to the coast, which are generated by radiation tensions.

It should be noted that due to the absence of field measurements, the accuracy of the results cannot be verified absolutely. However, the LITPACK numerical model uses more detailed and more precise parameters in its calculations than the empirical relationships and is generally more reliable. This model presents various capabilities, such as longshore flow modeling and rate of longshore sediment transport induced by waves and currents, taking into account the phenomena affecting wave transfer. In addition, because the values obtained for sediment load are based on the sediment transport potential, and it occurs if the sediment load is sufficient at the upstream, actual sediment transport may actually be less than that obtained in the simulations.

The amount of sediment build-up behind the breakwater is similar to Figure 7. As can be observed, after 1, 5, 10 and 12 years, the sedimentation rate behind the port is $81,190,247$ and 267 meters, respectively. Since the length of the breakwaters is 300 meters, the sedimentation problem has not emerged yet for the port after 12 years.

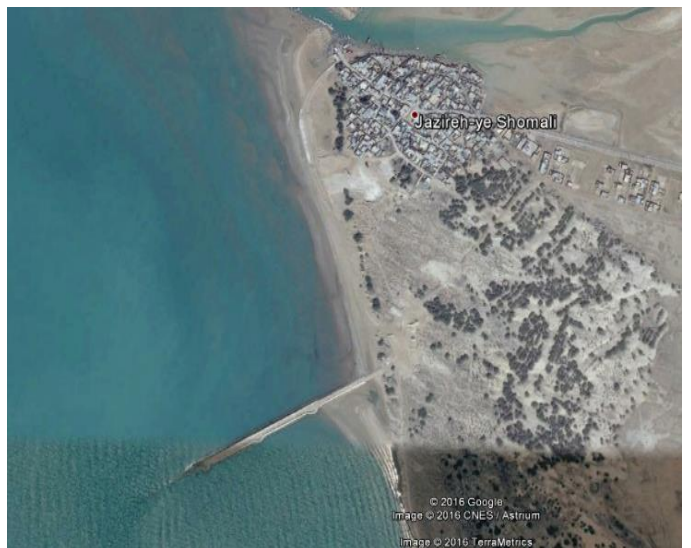

Figure 7: Sedimentation behind the Jazireh-e Shomali-Jonoubi Port's breakwater 
(C) 2012 ISOMAse, All rights reserved

The results of the numerical simulation of the sediment transport rate and shoreline changes are presented as diagrams in the following.

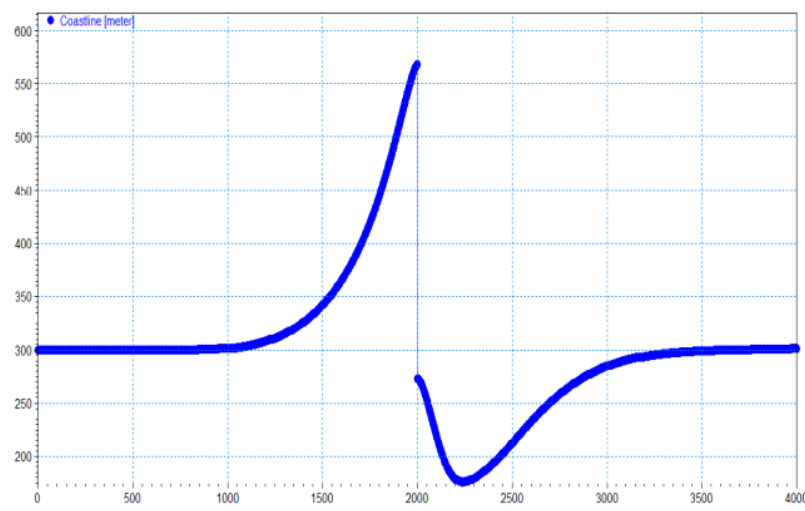

Figure 8: Shoreline changes of Jazireh-e Shomali-Jonoubi Port after 12 years

The values of the annual net and gross sediment transport rates are as follows (the net amount refers to the amount of the sediment transferred from the west to the east minus the amount transferred from the east to the west, as obtained according to the software. Also, the gross sediment transport is the sum of longshore sediment transport from the west to the east and from the east to the west).

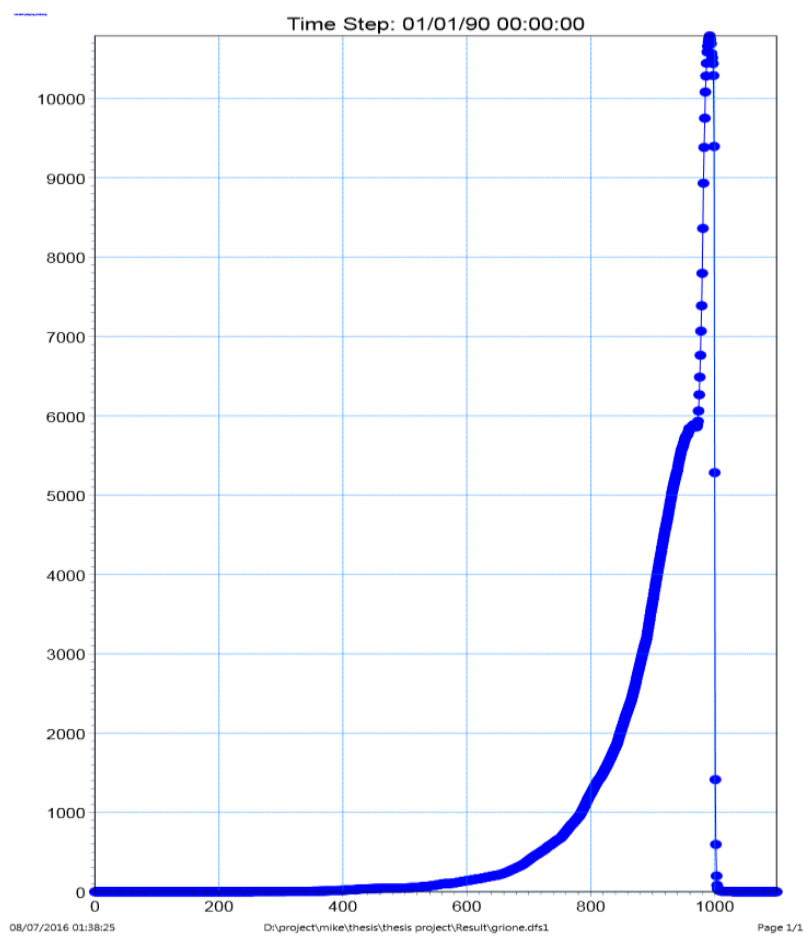

(a)

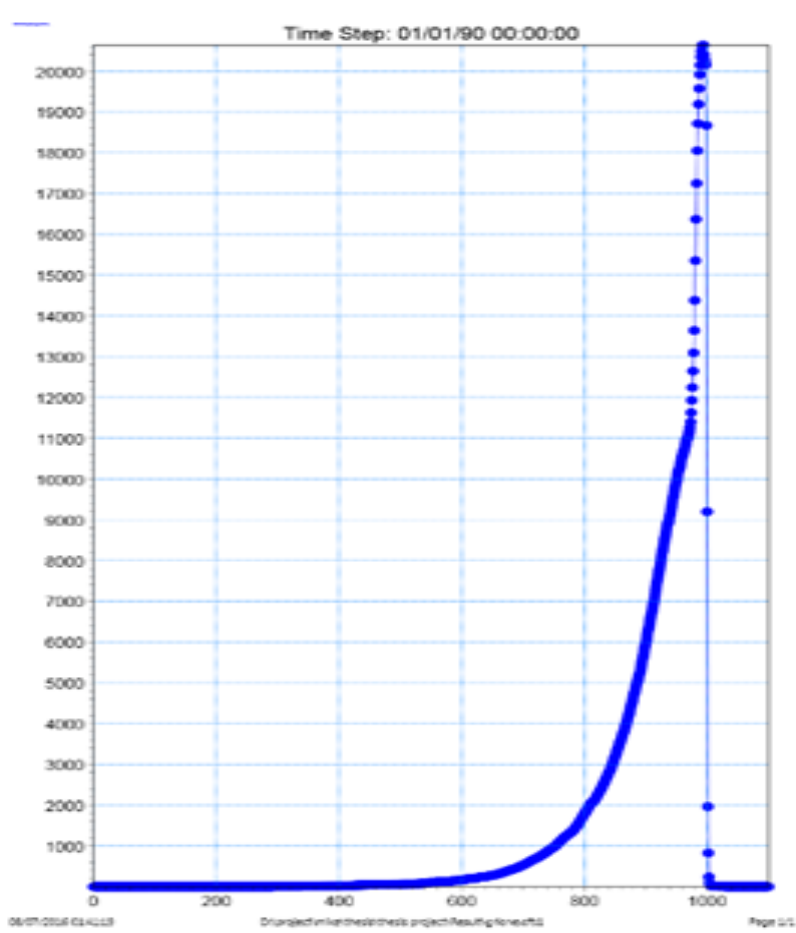

(b)

Figure 9: Amounts of the annual net and gross sediment transport

Also, the mean amount of annual sediment transport from the east to the west and from the west to the east is shown in Figure 10.

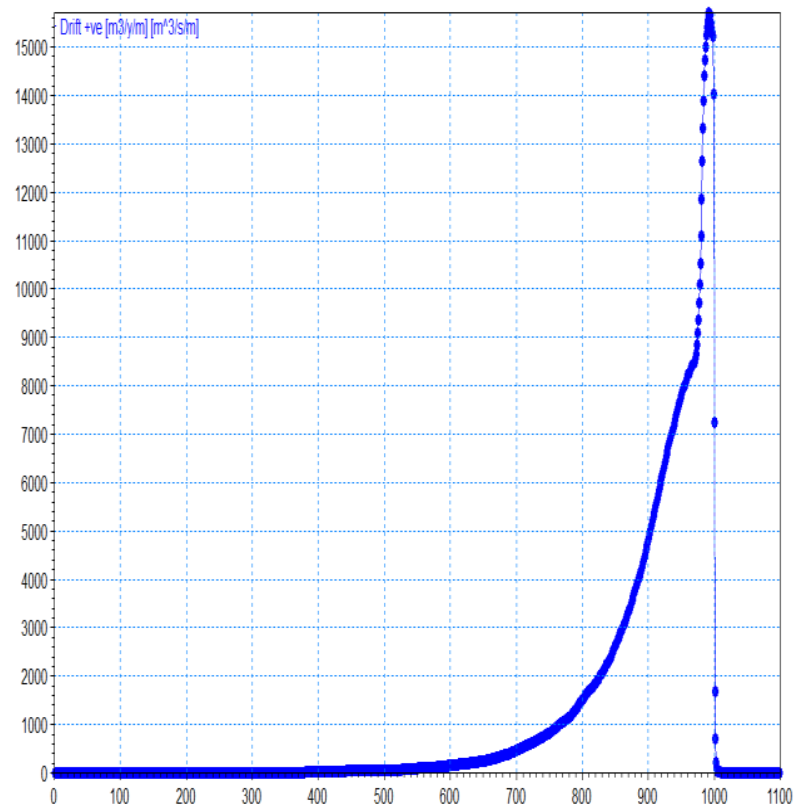

(a) 


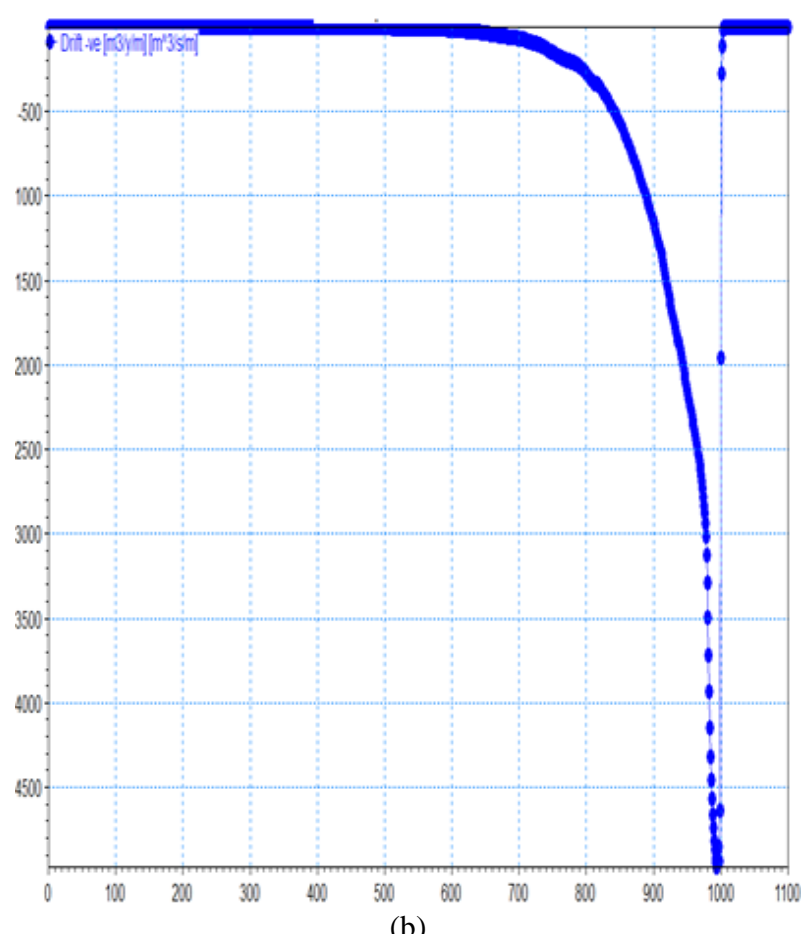

(b)

Figure 10: The mean amount of annual sediment transport from the east to the west and from the west to the east

Finally, the total volume of the accumulated sediment over 12 years is depicted in Figure 11.

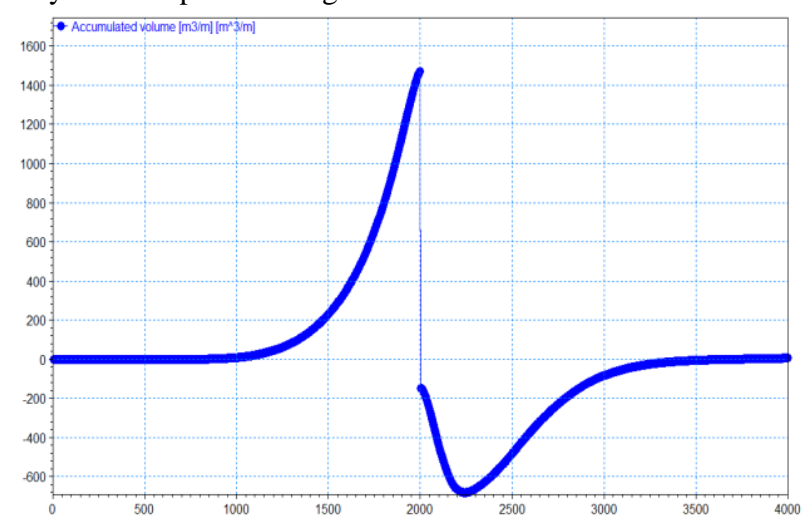

Figure 11: Diagram of sediment accumulation over 12 years

\subsection{CONCLUSION}

In this paper, sediment transport rates and shoreline changes of Jazireh-e Shomali-Jonoubi Port were modeled using the MIKE21 software. The results showed that in 12 years' time, the shoreline advances from 300 to $550 \mathrm{~m}$ from kilometer 0 to kilometer 2, and recedes to $270 \mathrm{~m}$ upon meeting the breakwater and continues this receding trend until it reaches zero at kilometer 2.25. The shoreline then moves forward until kilometer 3.5 and attains a constant value of $300 \mathrm{~m}$. As is evident from the diagrams of the annual net and gross sediment transport, the sediment transport rate increases by moving away from the breakwater and decreases by approaching the breakwater. The total volume of sediment accumulated over 12 years, rises from 0 to $1480 \mathrm{~m}^{3}$ from kilometer 0 to kilometer 2 of the shoreline and decreases to $120 \mathrm{~m}^{3}$ as it reaches the breakwater, and follows this decreasing trend until it reaches zero at kilometer 2.25. Afterward, the sediment accumulation volume increases again and reaches a constant zero value from kilometer 3.5 on.

\section{REFERENCE}

[1] Ahmadi, H. (2011). Erosion by water, In Applied Geomorphology, 2nd Edn., University of Tehran Publications, Tehran, Iran.

[2] Baquerizo, A., Losada, M.A. (2008). Human interaction with large-scale coastal morphological evolution; An Assessment of the Uncertainty, Coastal Engineering 55, 569-580.

[3] Barter, P.W.J., Burgess, K.A., Jay, H., Hosking, A.S.D. (2003). Future Coast: Predicting the Future Coastal Evolution of England and Wales, International Conference on Estuaries and Coasts, Hangzhou, China.

[4] Bayram, A., Larson, M., \& Hanson, H. (2007). A new formula for the total longshore sediment transport rate. Coastal Engineering, 54(9), 700-710.

[5] Boak, E.H., \& Turner, I.L. (2005). Shoreline definition and detection: a review. Journal of coastal research, 688703.

[6] Brown, J.M. \& Davies, A.G. (2009). Methods for medium-term prediction of the net sediment transport by waves and currents in complex coastal regions. Continental Shelf Research,29(11-12), 15021514.

[7] De Vriend, H. J. (1991). Mathematical Modelling and Large-scale Coastal Behaviour, Journal of Hydraulic Research, 29(6), 741-753.

[8] Ensign, S., Currin, C., Piehler, M., \& Tobias, C. (2017). A method for using shoreline morphology to predict suspended sediment concentration in tidal creeks. Geomorphology, 276, 280-288.

[9] Esteves, L.S., Williams, J.J. \& Lisniowski, M.A. (2009). Measuring and modeling longshore sediment transport. Estuarine, Coastal and Shelf Science, 83(1), 47-59.

[10] Gopikrishna, B. \& Deo, M.C. (2018). Changes in the shoreline at Paradip Port, India in response to climate change. Geomorphology, 303, 243-255.

[11] Hendriyono, W., Wibowo, M., Al Hakim, B. \& Istiyanto, D. C. (2015). Modeling of sediment transport affecting the coastline changes due to infrastructures in batang-central java. Procedia Earth and Planetary Science, 14, 166-178.

[12] Hopkins, J., Elgar, S. \& Raubenheimer, B. (2017). Flow separation effects on shoreline sediment transport. Coastal Engineering, 125, 23-27.

[13] Irtem, E., Kabdasli, S. \& Gedik, N. (2001). Analysis of shoreline changes by a numerical model and application to altınova, turkey. Journal of Coastal Research, 397-402.

[14] Jackson, N.L., Nordstrom, K.F. \& Farrell, E.J. (2017). Longshore sediment transport and foreshore change in the 
swash zone of an estuarine beach. Marine Geology, 386 , 88-97.

[15] Kaviani, M. (2001). Microclimatology, 1st Edn., Samt Publications, Tehran, Iran.

[16] Kouroshinia, A., (2010). Monitoring coastline changes using RS \& GIS, Bandar VA Darya Magazine, 175, 108111.

[17] Kulkarni, R.R. (2013). Numerical Modelling of Coastal Erosion using MIKE21, Master's thesis: Norwegian University of Science and Technology, Trondheim, Norway.

[18] Kumar, V.S., Anand, N.M., Chandramohan, P. \& Naik, G. N. (2003). Longshore sediment transport ratemeasurement and estimation, a central west coast of India. Coastal Engineering, 48(2), 95-109.

[19] Larson, M., Rosati, J.D., Kraus, N.C. (2002). Overview of regional coastal processes and controls, coastal and hydraulics engineering technical note CHETN-XIV-4, U.S. Army Engineer Research and Development Center, Vicksburg, MS.

[20] Li, M., Fernando, P.T., Pan, S., O'Connor, B.A., \& Chen, D. (2007). Development of a quasi-3d numerical model for sediment transport prediction in the coastal region. Journal of Hydro-environment Research, 1(2), 143-156.

[21] Nguyen, N.T. \& Luong, P.H. (2007). Studying shoreline change by using LITPACK mathematical model (case study in Cat Hai Island, Hai Phong City, Vietnam).

[22] Rajasree, B.R., Deo, M.C. \& Nair, L.S. (2016). Effect of climate change on shoreline shifts at a straight and continuous coast. Estuarine, Coastal and Shelf Science, 183, 221-234.

[23] Rasuly, A., Naghdifar, R. \& Rasoli, M., (2010). Monitoring of Caspian Sea coastline changes using objectoriented techniques, Procedia Environmental Sciences, 2, 416-426.

[24] Ruggiero, P. \& McDougal, W.G. (2001). An analytic model for the prediction of wave setup, longshore currents and sediment transport on beaches with seawalls. Coastal Engineering, 43(3-4), 161-182.

[25] Sabatier, F., Samat, O., Ullmann, A., Suanez, S. (2009). Connecting large-scale coastal behavior with the coastal management of rhône delta, Geomorphology 107, 79-89.

[26] Shanehsazzadeh, A., Parsa, R., Ardalan, H. (2012). Combination of large-scale and local shoreline change models for hormozgan coastline at the Northern Persian Gulf, the 10th International Conference on Coasts, Ports and Marine Structures, Iran.

[27] Townsend, K.E., Thomas, R.C. \& Frey, A.E. (2014). Shoreline Change Modeling Using One-Line Models: Application and Comparison of GenCade, Unibet, and Linpack (No. ERDC/CHL CHETN-IV-102). Army Corps of Engineer Vicburg MS Engineer Research and Development Center.
[28] Walton, T.L. \& Chiu, T.Y. (1979). A review of analytical techniques to solve the sand transport equation and some simplified solutions. In Coastal Structures, 79, 809-837. ASCE.

[29] Winareso, G. and Budhiman, S., (2001). The potential application of remote sensing data for the coastal study, Proc. of 22nd Asian Conference on Remote Sensing, 2, Singapore, 1-5.

[30] Yamani, M. and Nohegar, A. (2006). Coastal area location and literature review, In the Geomorphology of East Coast of Hormoz Strait, 1st Edn., 7-83, University of Hormozgan Publications, Bandar-e-Abbas, Iran. 